\title{
A Rotor Flux and Speed Observer for Sensorless Single-Phase Induction Motor Applications
}

\author{
Massimo Caruso, ${ }^{1}$ Vittorio Cecconi, ${ }^{1}$ Antonino O. Di Tommaso, ${ }^{1}$ and Ronilson Rocha ${ }^{2}$ \\ ${ }^{1}$ Department of Electrical, Electronics and Telecommunications Engineering, University of Palermo, Vialle delle Scienze, Edificio 9 , \\ 90128 Palermo, Italy \\ ${ }^{2}$ Department of Control and Automation Engineering, School of Mines, Federal University of Ouro Preto, Campus Morro do Cruzeiro, \\ 35400-000 Ouro Preto, MG, Brazil
}

Correspondence should be addressed to Ronilson Rocha, rocha@decat.em.ufop.br

Received 6 October 2011; Revised 5 January 2012; Accepted 26 January 2012

Academic Editor: Hyeong Joon Ahn

Copyright ( $) 2012$ Massimo Caruso et al. This is an open access article distributed under the Creative Commons Attribution License, which permits unrestricted use, distribution, and reproduction in any medium, provided the original work is properly cited.

It is usual to find single-phase induction motor (SPIM) in several house, office, shopping, farm, and industry applications, which are become each time more sophisticated and requiring the development of efficient alternatives to improve the operational performance of this machine. Although the rotor flux and rotational speed are essential variables in order to optimize the operation of a SPIM, the use of conventional sensors to measure them is not a viable option. Thus, the adoption of sensorless strategies is the more reasonable proposal for these cases. This paper presents a rotor flux and rotational speed observer for sensorless applications involving SPIMs. Computer simulations and the experimental results are used to verify the performance of the proposed observer.

\section{Introduction}

The single-phase induction motor (SPIM) has a very robust design and can be mass produced with relatively low cost. Traditionally used in fractional and subfractional horsepower applications, it is usual to find this motor in several house, office, shopping, farm, and industry appliances such as air conditioning systems, mixers, washers, blowers, dryers, fans, refrigerators, vacuum cleaners, compressors, pumps, and so forth. Due to introduction of low-cost static power converters and the development of more sophisticated appliances, the traditional SPIM applications have required the development of efficient alternatives to improve the performance of this machine.

The SPIM is basically constituted by a squirrel-cage rotor and two stator windings displaced $90^{\circ}$ in space, known as main and auxiliary windings. This machine is usually unbalanced, and its windings present different impedances. When the main winding is fed by a single-phase source, the produced magnetic field is pulsating and stationary, and a starting torque is not developed. To start a SPIM, the auxiliary winding must emulate a second phase. Although the auxiliary winding is often disconnected by a centrifugal switch when the SPIM rotor reaches $60 \%$ to $80 \%$ of rated speed, it can be maintained at running operation in order to provide a higher and less pulsating torque. In general, a series capacitor is connected with the auxiliary winding in order to improve the starting and the SPIM performance.

Many proposals for the better performance of a SPIM are based in the use of an electronically switched series capacitor in the auxiliary winding, which can be controlled to improve the machine performance at different operating conditions $[1-4]$. The variable speed drives are also proposed in several SPIM applications in order to provide energy savings and torque improvement [5-13]. Although the magnetic flux and/or rotational speed of this machine are essential variables in order to optimize the performance of a SPIM, the use of sensors to measure them cannot be justified in fractional and low-cost SPIM applications since then implies in more electronics, higher cost, lower reliability, assembling difficulties, and the increase in weight, size, and electrical susceptibility. Considering these problems, the adoption of a sensorless strategy is a more reasonable option for high-performance SPIM applications, where the magnetic flux and/or rotational speed are estimated from stator voltage and current measurements $[4,12,14-17]$. 


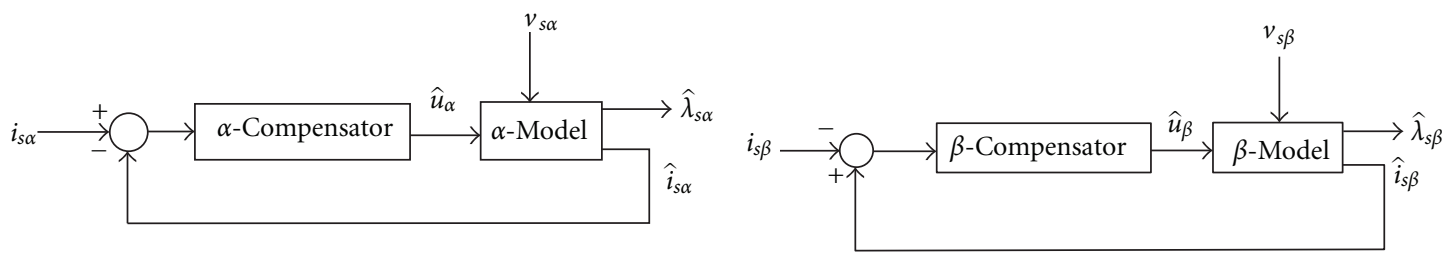

Figure 1: $\alpha$ - and $\beta$-Flux observer structures.

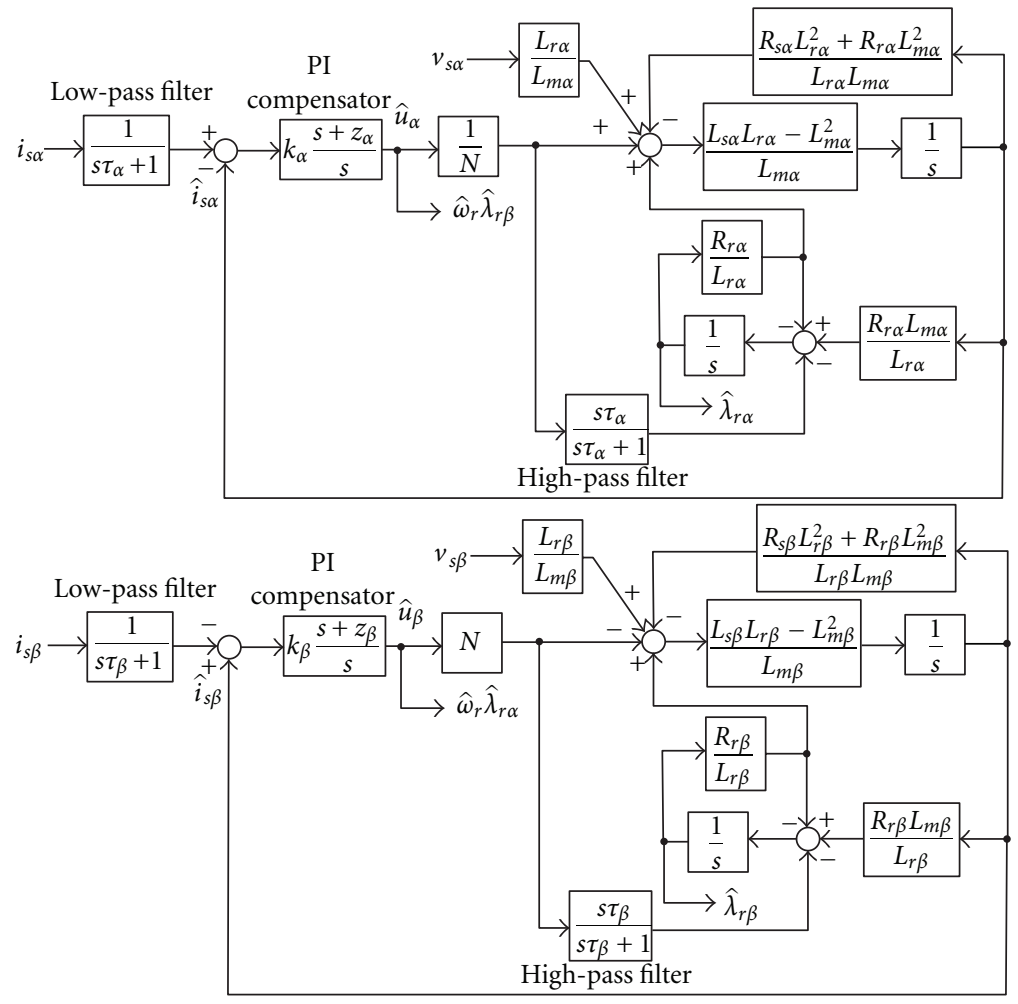

FIgURE 2: Block diagram of $\alpha$ - and $\beta$-flux observers.

This paper presents an original proposal of a rotor flux observer for SPIM, from which the rotor speed of this motor can be estimated. This observer can be used in applications involving SPIMs that require the estimation of rotor flux and/or rotor speed, such as optimization strategies, sensorless vector control of the machine based on the philosophy of the direct flux orientation, and so forth. Two half flux observers are designed using the stationary reference frame SPIM model. From these half flux observers, data are obtained to estimate the rotor speed of the SPIM. The performance of the proposed observer is satisfactorily demonstrated from computer simulations and experimental tests considering two situations: a step variation in the stator frequency of the no load SPIM and the application of mechanical load to SPIM shaft.

\section{Flux Observer}

Traditionally, the dynamic model of a SPIM is described considering a stationary reference frame $\alpha-\beta$ fixed in the stator, where $\alpha$ and $\beta$ denote the auxiliary and main windings respectively [18]. If the stator currents $i_{s}$ and the rotor flux $\lambda_{r}$ vectors are admitted as the state variables, this dynamic model can be written as follows [17]:

(i) $\alpha$-model

$$
\begin{gathered}
\dot{i}_{s \alpha}=\frac{L_{m \alpha}}{L_{\sigma \alpha}}\left(\frac{L_{r \alpha}}{L_{m \alpha}} v_{s \alpha}+\frac{R_{r \alpha}}{L_{r \alpha}} \lambda_{r \alpha}-\frac{R_{\phi \alpha}}{L_{r \alpha} L_{m \alpha}} i_{s \alpha}+\frac{u_{\alpha}}{N}\right), \\
\dot{\lambda}_{r \alpha}=-\frac{R_{r \alpha}}{L_{r \alpha}}\left(\lambda_{r \alpha}-L_{m \alpha} i_{s \alpha}\right)-\frac{u_{\alpha}}{N},
\end{gathered}
$$

(ii) $\beta$-model

$$
\begin{gathered}
\dot{i}_{s \beta}=\frac{L_{m \beta}}{L_{\sigma \beta}}\left(\frac{L_{r \beta}}{L_{m \beta}} v_{s \beta}+\frac{R_{r \beta}}{L_{r \beta}} \lambda_{r \beta}-\frac{R_{\phi \beta}}{L_{r \beta} L_{m \beta}} i_{s \beta}-N u_{\beta}\right), \\
\dot{\lambda}_{r \beta}=-\frac{R_{r \beta}}{L_{r \beta}}\left(\lambda_{r \beta}-L_{m \beta} i_{s \beta}\right)+N u_{\beta},
\end{gathered}
$$




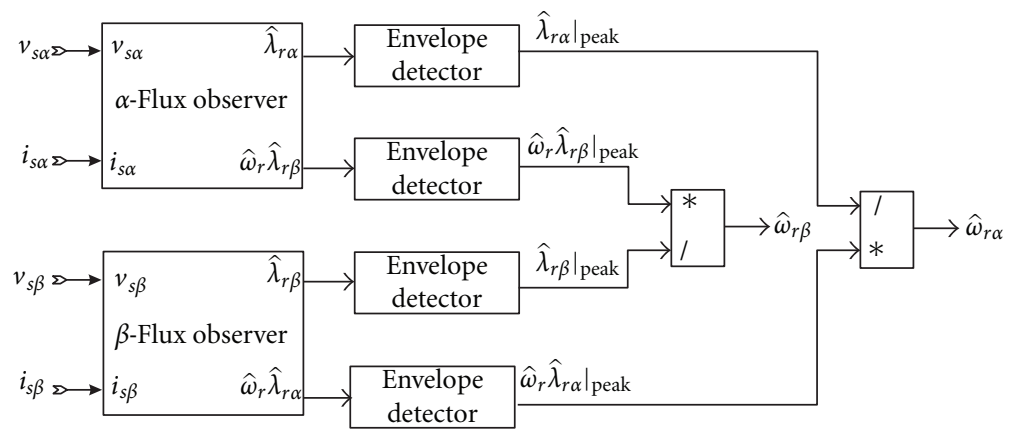

FIgURE 3: Speed estimation using flux observers and envelope detectors.

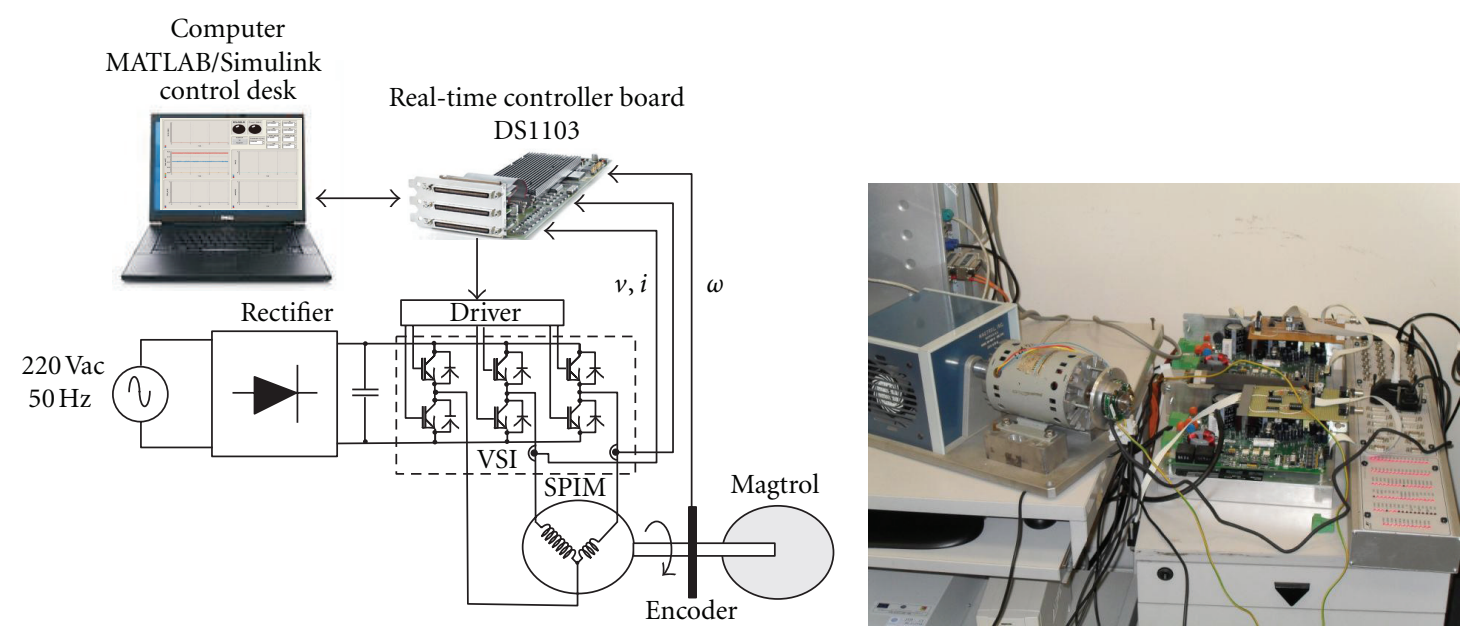

FIgURE 4: SPIM test bench.

TABle 1: SPIM data.

\begin{tabular}{|c|c|c|c|}
\hline \multicolumn{4}{|c|}{ Rated values } \\
\hline Volt & & \multicolumn{2}{|c|}{$110 \mathrm{~V}$} \\
\hline Frec & & \multicolumn{2}{|c|}{$50 / 60 \mathrm{~Hz}$} \\
\hline Mai & current & \multicolumn{2}{|c|}{$2.3 \mathrm{~A}$} \\
\hline Spee & & \multicolumn{2}{|c|}{$2700 \mathrm{RPM}$} \\
\hline No. & & \multicolumn{2}{|c|}{2} \\
\hline Pow & & \multicolumn{2}{|c|}{$0.25 \mathrm{HP}(180 \mathrm{~W})$} \\
\hline \multicolumn{2}{|c|}{ Main winding $(\beta)$} & \multicolumn{2}{|c|}{ Auxiliary winding $(\alpha)$} \\
\hline$R_{s \beta}$ & $5.2 \Omega$ & $R_{s \alpha}$ & $29 \Omega$ \\
\hline$R_{r \beta}$ & $9.4 \Omega$ & $R_{r \alpha}$ & $35.9 \Omega$ \\
\hline$L_{m \beta}$ & $0.3 \mathrm{H}$ & $L_{m \alpha}$ & $0.45 \mathrm{H}$ \\
\hline$L_{s \beta}$ & $0.3068 \mathrm{H}$ & $L_{s \alpha}$ & $0.55 \mathrm{H}$ \\
\hline$L_{r \beta}$ & $0.3068 \mathrm{H}$ & $L_{r \alpha}$ & $0.55 \mathrm{H}$ \\
\hline \multicolumn{2}{|c|}{$N=N_{\beta} / N_{\alpha}$} & \multicolumn{2}{|c|}{0.67} \\
\hline
\end{tabular}

where $v_{s}=$ stator voltage, $\omega_{r}=$ rotational speed, $u_{\alpha}=\omega_{r} \lambda_{r \beta}$, $u_{\beta}=\omega_{r} \lambda_{r \alpha}, R=$ resistance, $L=$ winding inductance, $L_{m}=$ mutual inductance, $R_{\phi}=R_{s} L_{r}^{2}+R_{r} L_{m}^{2}, L_{\sigma}=L_{s} L_{r}-L_{m}^{2}$, and $N=$ transformer ratio between both stator windings. The subscripts $s$ and $r$ are related, respectively, to stator and rotor variables and parameters.
TABLE 2: Electrical characteristics of the IGBT power converter.

\begin{tabular}{lc}
\hline Input voltage (single phase) & $230 \mathrm{VCA}$ \\
Motor supply rail & $310 \mathrm{VDC}$ \\
Output power peak & $6.5 \mathrm{~kW}$ \\
Phase current peak (crest) & $30 \mathrm{~A}$ \\
Phase current cont. & $21 \mathrm{~A}(\mathrm{RMS})$ \\
Switching frequency & 5 to $20 \mathrm{kHz}$ \\
Shunt power peak & $3200 \mathrm{~W}$ \\
\hline
\end{tabular}

In order to obtain the convergence of the observed variables to its real value in conventional state observers, a correctional term is usually inserted in the system model to reduce the error between the measurable variables and their respective estimated values. If this principle is applied to observe the rotor fluxes of a SPIM, the resulting observer is nonlinear, since the terms $u_{\alpha}$ and $u_{\beta}$ consist in the product of two state variables of the system. However, if these nonlinear terms $u_{\alpha}$ and $u_{\beta}$ of SPIM model are considered to correct the observation error, the flux observer can be decoupled in two linear and independent closed-loop systems as shown in Figure 1, which can be designed and analyzed using linear techniques. Another advantage of this proposed structure for 


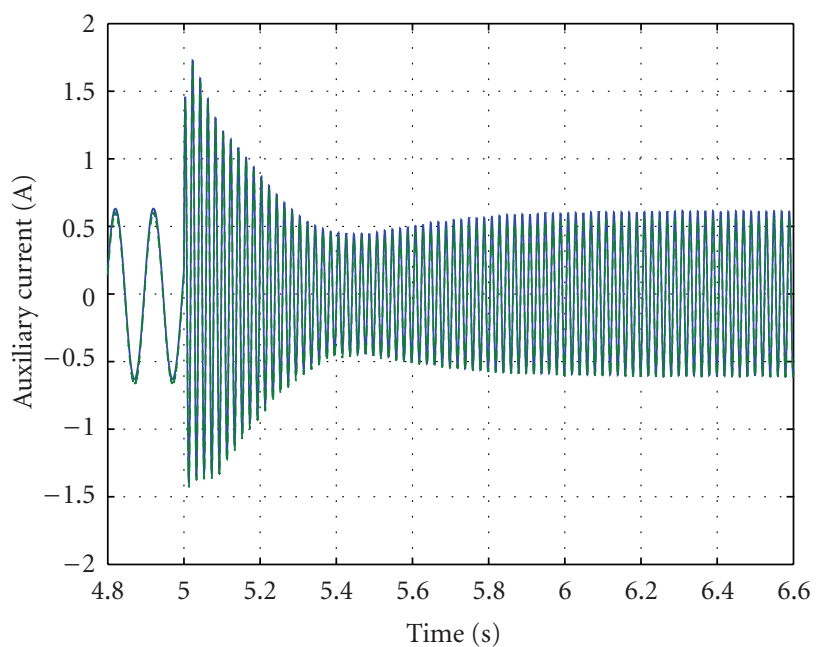

(a)

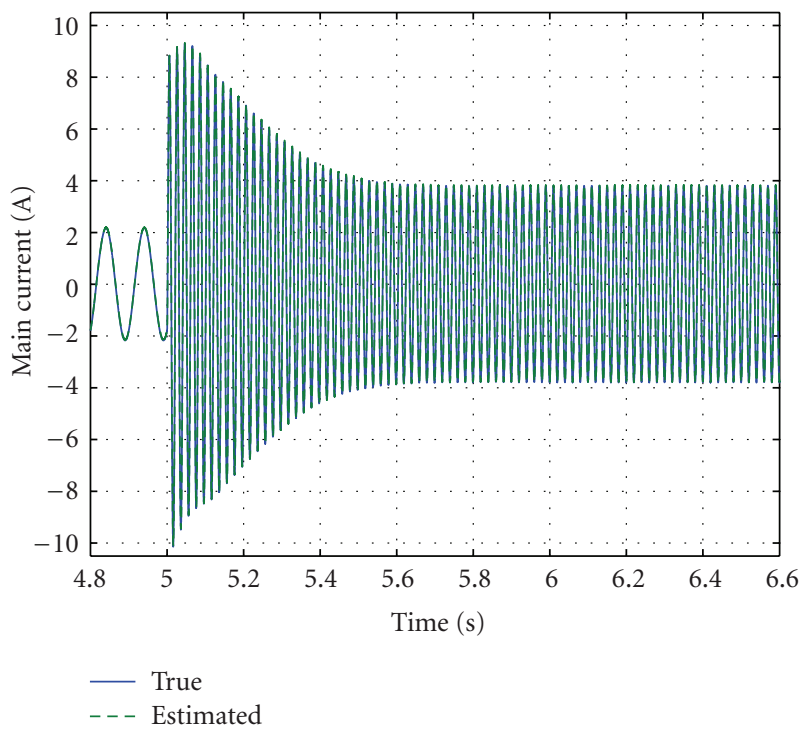

(c)

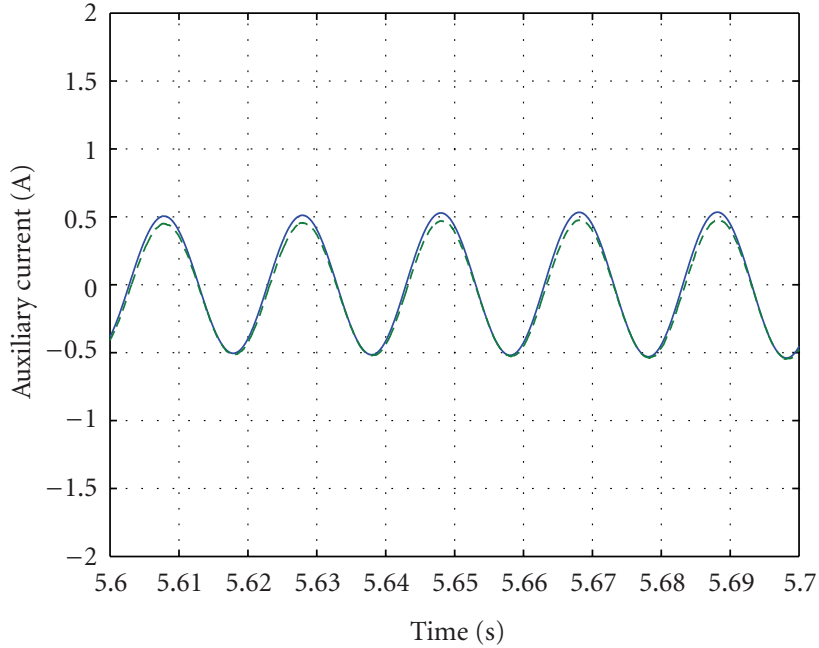

(b)

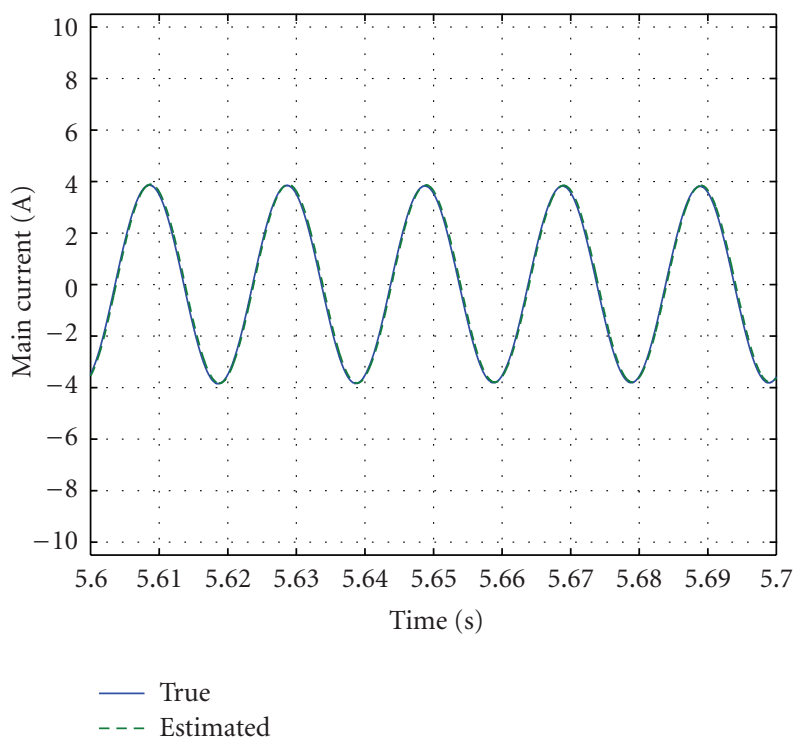

(d)

FIGURE 5: Stator currents of the no-load SPIM and their estimated values during a step variation from $10 \mathrm{~Hz}$ to $50 \mathrm{~Hz}$ in the stator frequency (computational simulation): (a) auxiliary winding $i_{s \alpha}$, (b) details of $i_{s \alpha}$, (c) main winding $i_{s \beta}$, (d) details of $i_{s \beta}$.

rotor flux observer is the possibility to evaluate the rotor speed of the SPIM, as will be seen in the next section.

Considering only the structure of $\beta$-flux observer shown in Figure 1, the open-loop transfer function between $\hat{i}_{s \beta}$ and $\hat{u}_{\beta}$ admitting $v_{s \beta}$ as system disturbance is given by

$$
\frac{\widehat{I}_{s \beta}(s)}{\widehat{U}_{\beta}(s)}=\frac{-s N L_{m \beta}}{s^{2} L_{\sigma \beta}+s R_{\sigma \beta}+R_{s \beta} R_{r \beta}},
$$

where $R_{\sigma \beta}=R_{r \beta} L_{s \beta}+R_{s \beta} L_{r \beta}$. This transfer function has a zero in the origin and two real poles. This zero provides a derivative action, which does not contribute to reduce the current error. Furthermore, this derivative action increases the observer sensitive to noises and disturbances. In order to prevent the effects of derivative action, a PI structure is considered for $\beta$-compensator:

$$
\frac{\hat{U}_{\beta}(s)}{\widehat{I}_{s \beta}(s)-I_{s \beta}(s)}=k_{\beta} \frac{s+z_{\beta}}{s},
$$

where the pure integrator of $\beta$-compensator eliminates the derivative action of $\beta$-model. The zero $z_{\beta}$ of the $\beta$-compensator can be chosen to cancel the slowest pole of the open-loop transfer function of (3). Since the PI compensator and the SPIM model are inherently stable, the Bode criteria can be 


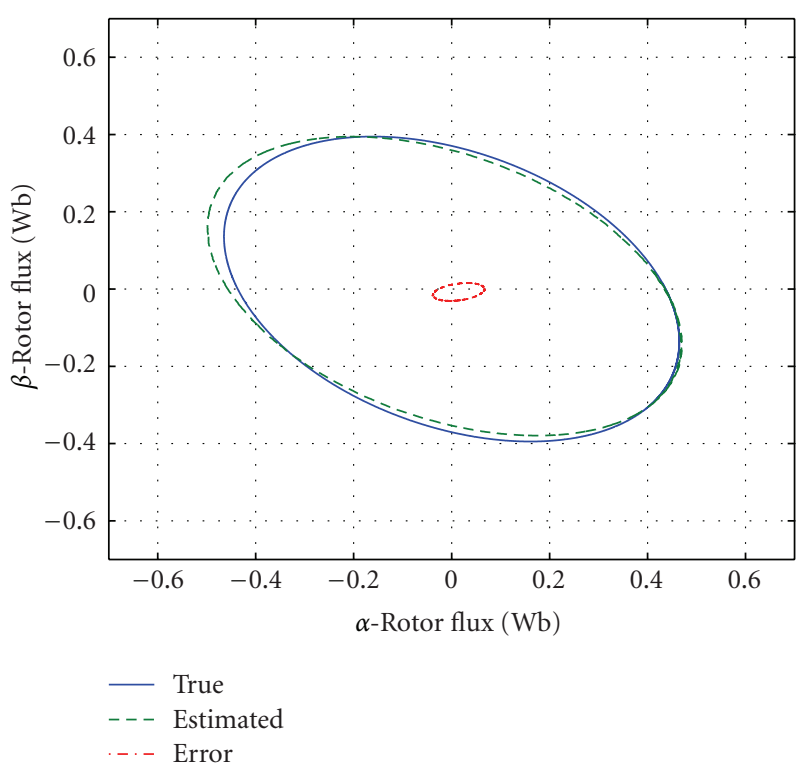

(a)

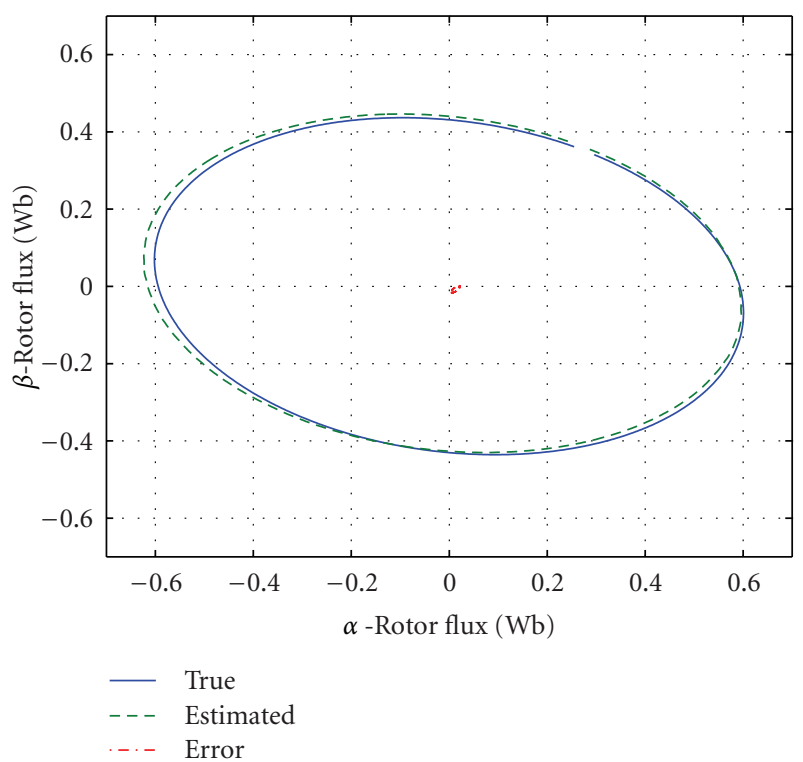

(b)

Figure 6: Phase portrait $\lambda_{r \alpha} \times \lambda_{r \beta}$ of the vector rotor flux of no-load SPIM (computational simulation): (a) $10 \mathrm{~Hz}$, (b) $50 \mathrm{~Hz}$.

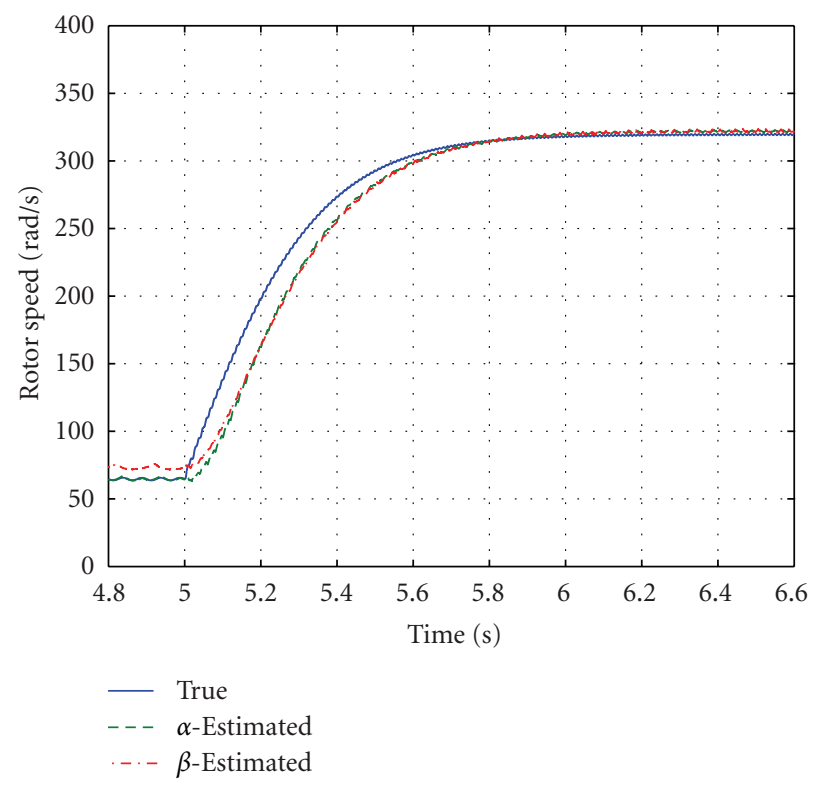

(a)

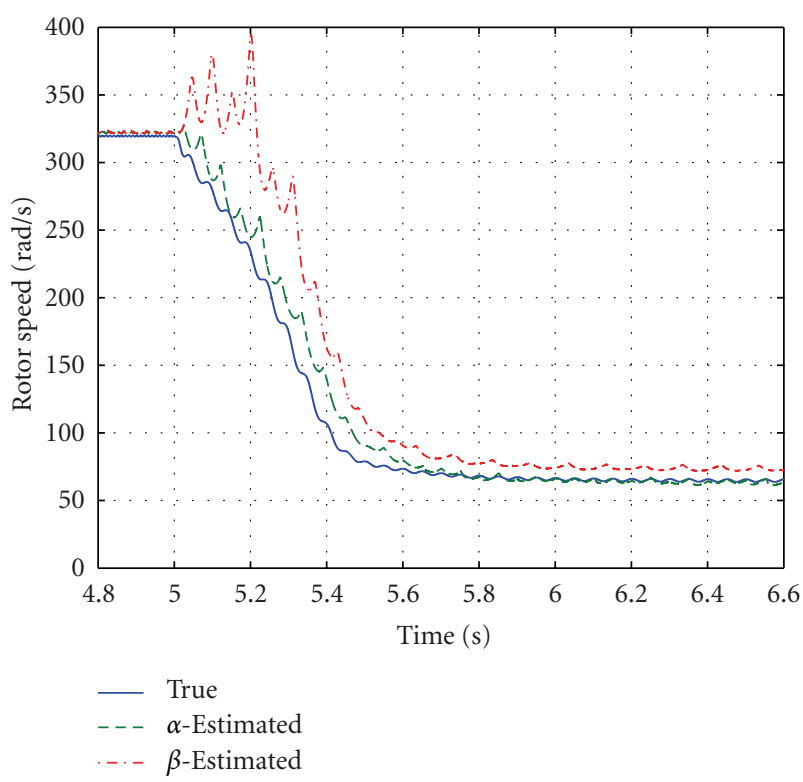

(b)

FIgURE 7: Rotor speed $\omega_{r}$ of the SPIM and its estimations $\widehat{\omega}_{r \alpha}$ and $\widehat{\omega}_{r \beta}$ during steps in the frequency stator (computational simulation): (a) from $10 \mathrm{~Hz}$ to $50 \mathrm{~Hz}$, (b) from $50 \mathrm{~Hz}$ to $10 \mathrm{~Hz}$.

used in order to verify the stability of the proposed structure for rotor flux observation. The proposed design of the PI compensator imposes a pole-zero cancellation in the openloop transfer function $\hat{I}_{s \beta} /\left(\hat{I}_{s \beta}-I_{s \beta}\right)$, assuring that the slope of the amplitude diagram will be always $-20 \mathrm{db} / \mathrm{dec}$ and the phase angle is always smaller than $135^{\circ}$ in the cross-over frequency. Thus, the proposed flux observer will be always stable in these circumstances independently of the gain $k_{\beta}$. This compensator provides an effective proportional action and, consequently, an offset error will always be present in the observation of $\beta$-flux. The performance of this structure is determined by the gain $k_{\beta}$, which can be chosen in order to obtain a fastest response and minimize the influence of the parameter variations over the flux estimation. 


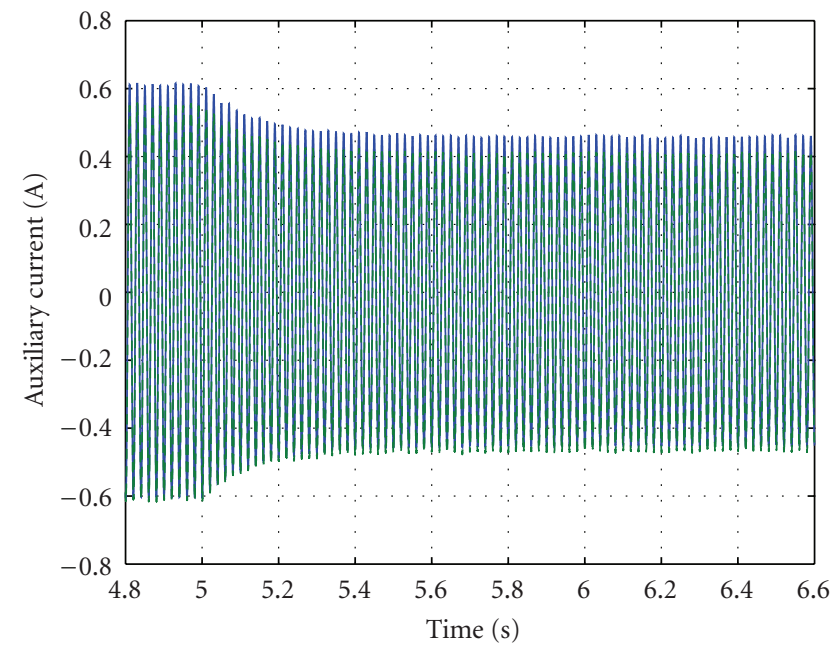

(a)

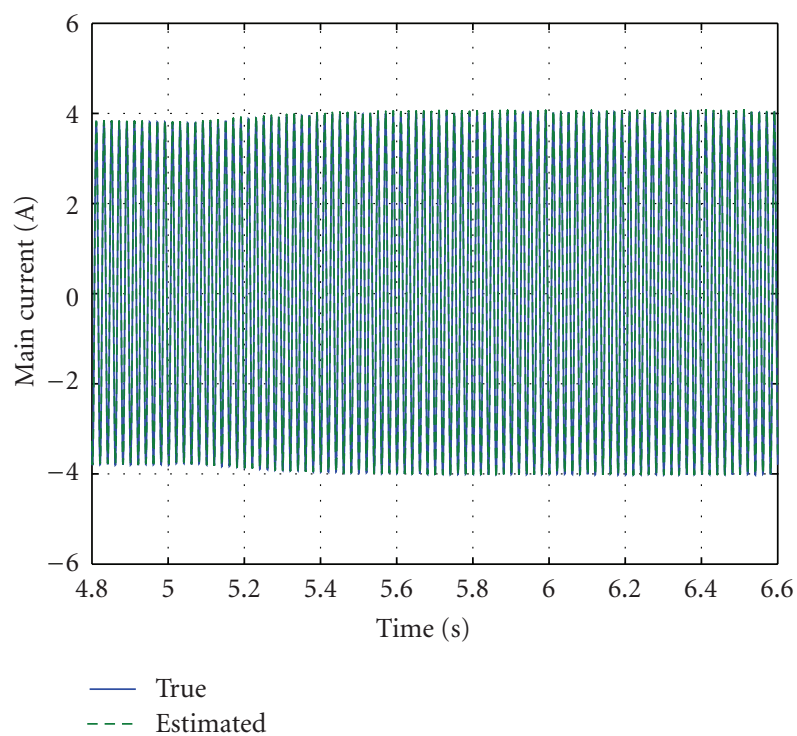

(c)

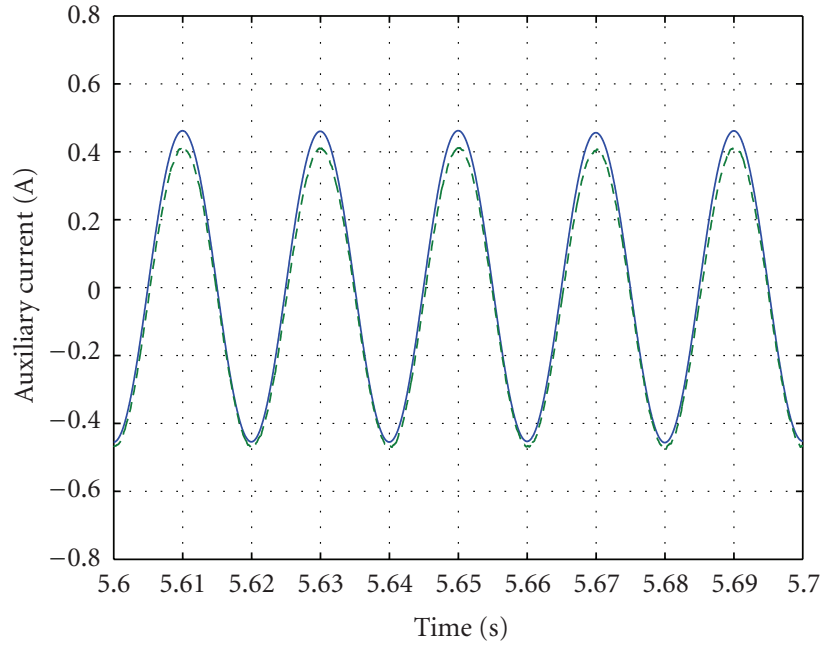

(b)

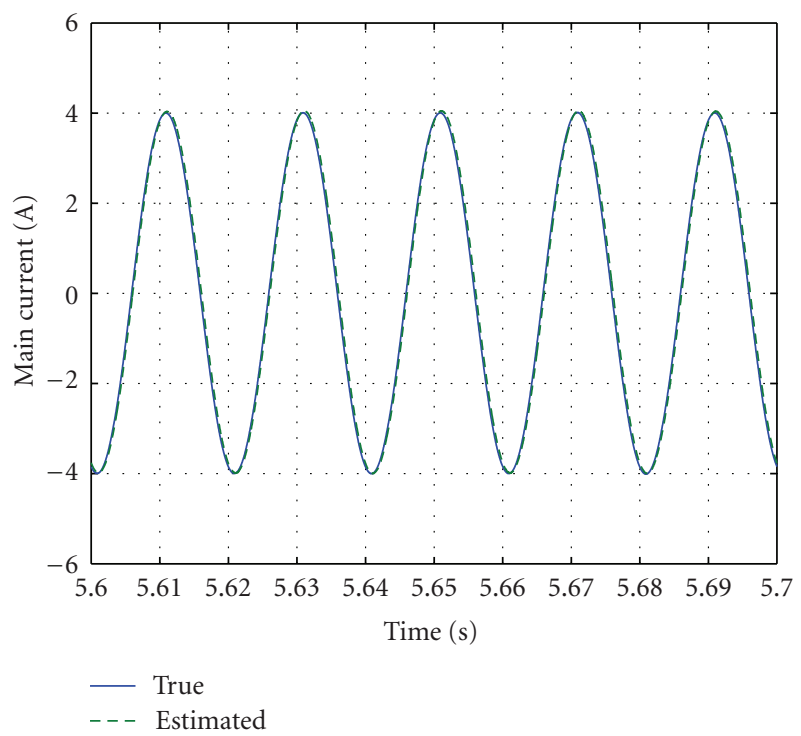

(d)

FIGURE 8: Stator currents of the SPIM and their estimated values for $50 \mathrm{~Hz}$ during a load step (computational simulation): (a) auxiliary winding $i_{s \alpha}$, (b) details of $i_{s \alpha}$, (c) main winding $i_{s \beta}$, (d) details of $i_{s \beta}$.

Considering the close-loop $\beta$-observer with a PI compensator, the transfer function between the estimated rotor flux $\hat{\lambda}_{r \beta}$ and the measurement $i_{s \beta}$ is given by

$$
\begin{aligned}
\frac{\hat{\Lambda}_{r \beta}(s)}{I_{s \beta}(s)}= & -\frac{s N k_{\beta}+N k_{\beta} z_{\beta}}{s} \\
& \times \frac{s L_{\sigma \beta}+R_{s \beta} L_{r \beta}}{s^{2} L_{\sigma \beta}+s\left(R_{\sigma \beta}+N k_{\beta} L_{m \beta}\right)+\left(R_{s \beta} R_{r \beta}+N k_{\beta} z_{\beta} L_{m \beta}\right)},
\end{aligned}
$$

where it is observed that the PI compensator introduces a pure integrator in the path of the estimated flux. This fact can compromise the performance of the proposed observer, since any DC offset in the current sensors will be continuously integrated until the saturation of the integrators. In order to prevent this problem, a first-order high-pass filter with a very low cut-off frequency (around $\mathrm{Hz}$ ) must be inserted in the path of the estimated flux to cancel the effects of the pure integrator introduced by PI compensator. Although this solution can deteriorate the dynamical performance of the proposed flux observer at very low rotor speed, it is satisfactory for the most of SPIM applications which usually do not work in this speed range. In order to reduce the effect of measurement noises in the observer performance, a first-order low-pass filter with an adequate cut-off frequency could be inserted in the measured current input to filter high-frequency signals. 


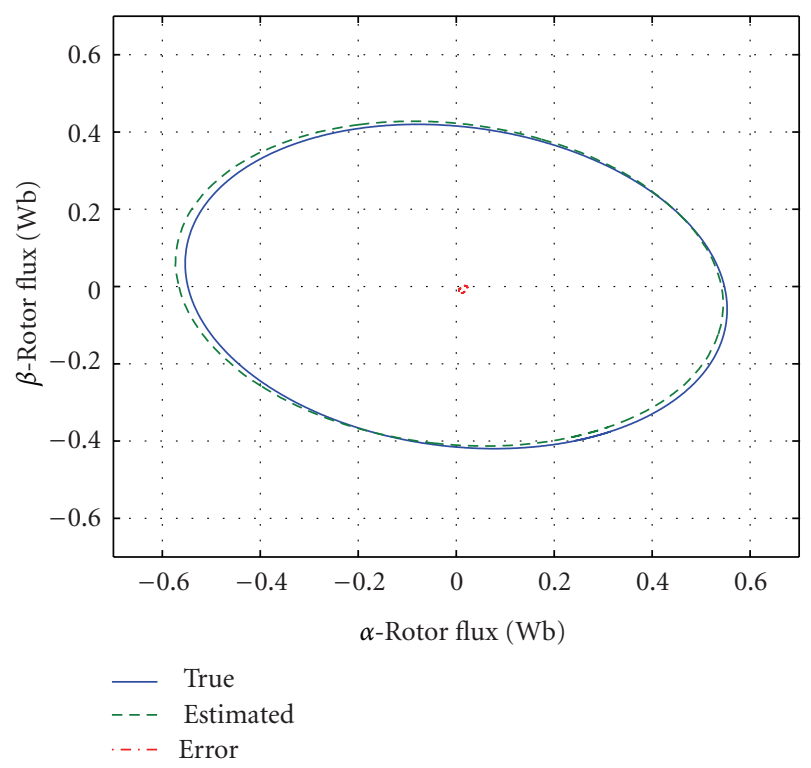

FIgURE 9: Phase portrait $\lambda_{r \alpha} \times \lambda_{r \beta}$ of rotor flux for $50 \mathrm{~Hz}$ considering the loaded SPIM (computational simulation).

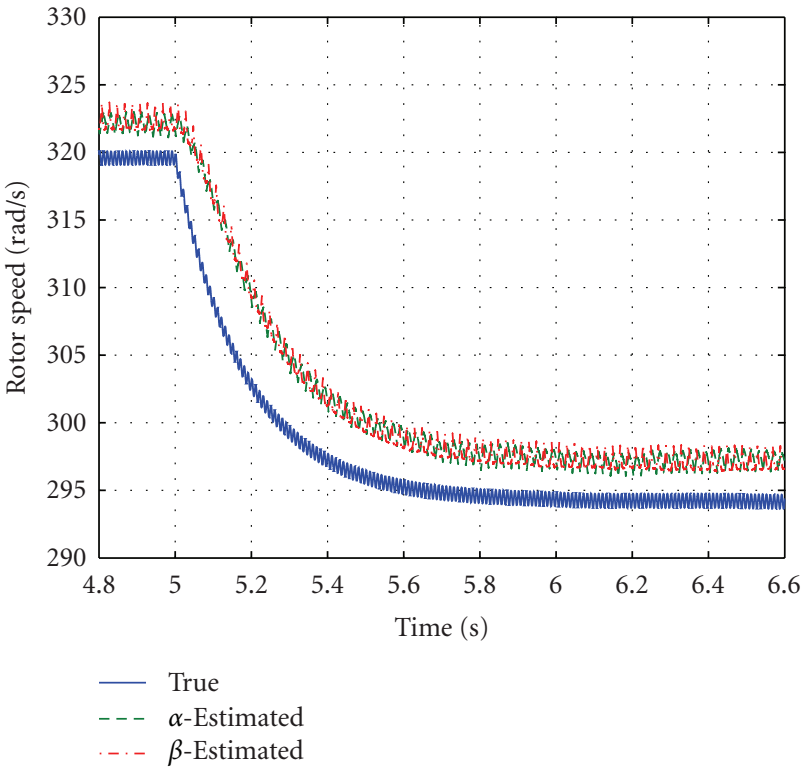

FIGURE 10: Rotor speed $\omega_{r}$ and its estimations $\widehat{\omega}_{r \alpha}$ and $\widehat{\omega}_{r \beta}$ for $50 \mathrm{~Hz}$ during the application of a load step (computational simulation).

The design of close-loop $\alpha$-flux observer is analogous to close-loop $\beta$-flux observer. The complete block diagram of the proposed flux observer is presented in the Figure 2. The basic difference between both observers is the form as the error signal must be computed, since the close-loop $\beta$-flux observer presents a reverse action.

\section{Rotor Speed Estimation}

If the observation of the rotor fluxes is satisfactory, an estimative of the rotor speed $\hat{\omega}_{r}$ can be obtained from the proposed flux observers for sensorless applications. Since the outputs of the PI compensators correspond to nonlinear terms, $\hat{u}_{\alpha}=$ $\widehat{\omega}_{r} \hat{\lambda}_{r \beta}$ and $\hat{u}_{\beta}=\hat{\omega}_{r} \hat{\lambda}_{r \alpha}, \hat{\omega}_{r}$ can be estimated dividing $\hat{u}_{\alpha}$ by $\hat{\lambda}_{r \beta}$ or $\hat{u}_{\beta}$ by $\hat{\lambda}_{r \alpha}$. Since $\hat{\lambda}_{r \alpha}$ and $\hat{\lambda}_{r \beta}$ are AC values, the computation of $\hat{\omega}_{r}$ is subject to a singularity due to zero division. In order to avoid this problem, the solution adopted in this work is only to compute $\hat{\omega}_{r}$ using the peak values of the signals $u_{\alpha}$ (or $u_{\beta}$ ) and $\lambda_{r \beta}$ (or $\lambda_{r \alpha}$ ), which occur simultaneously and can be captured using envelope detectors as shown in Figure 3.

\section{Experimental Test Bench}

The experimental apparatus shown in Figure 4 is used to verify the performance of the proposed rotor flux/speed observer. The data of the SPIM used in test bench are in Table 1, 


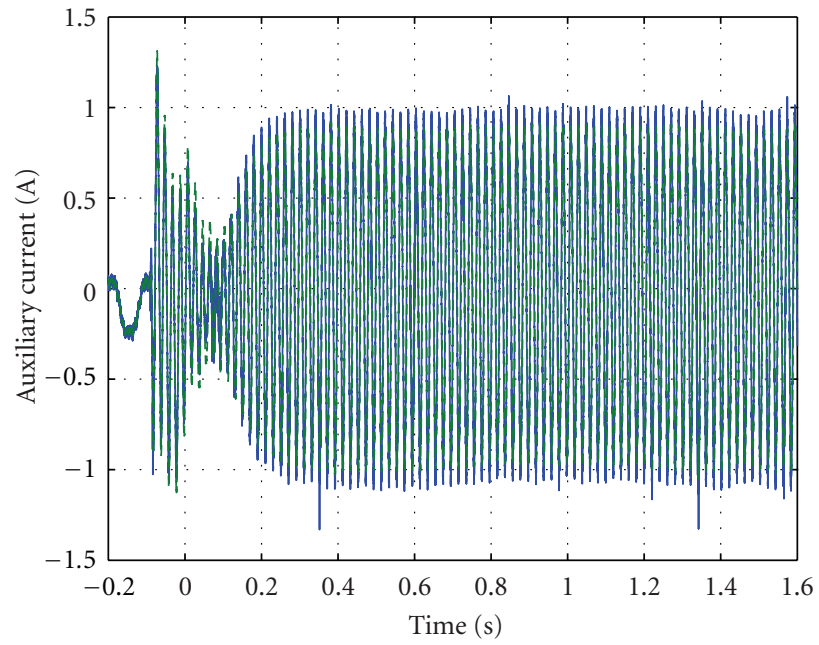

(a)

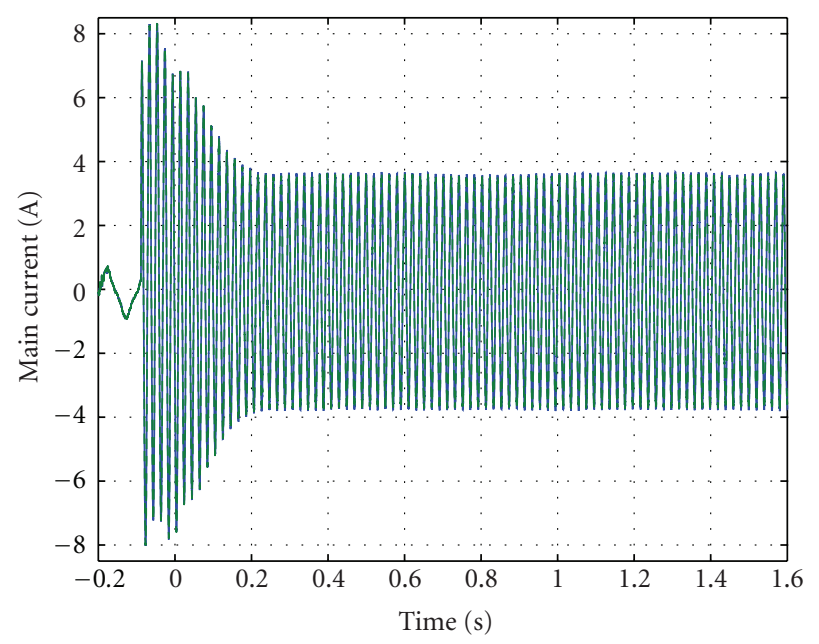

- Measured

- - - Estimated

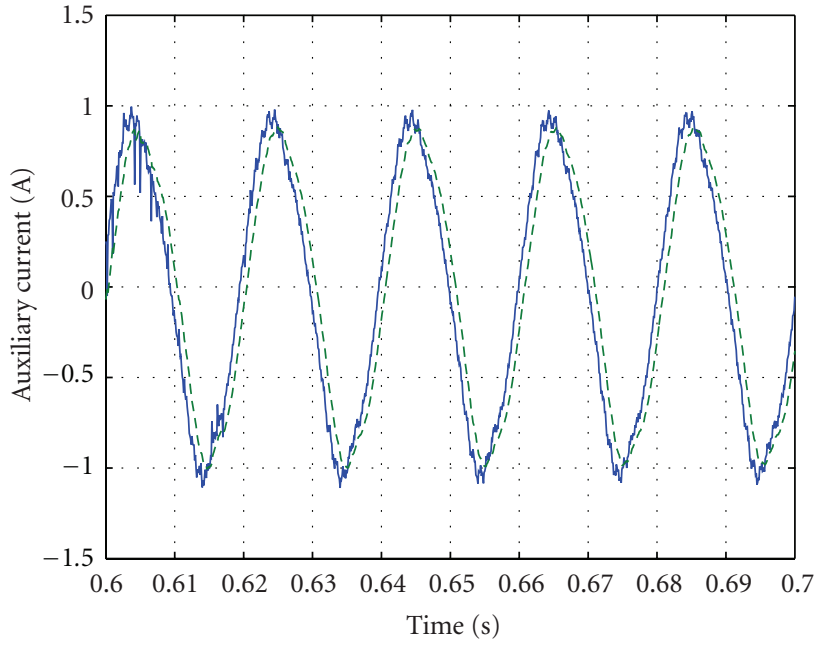

(b)

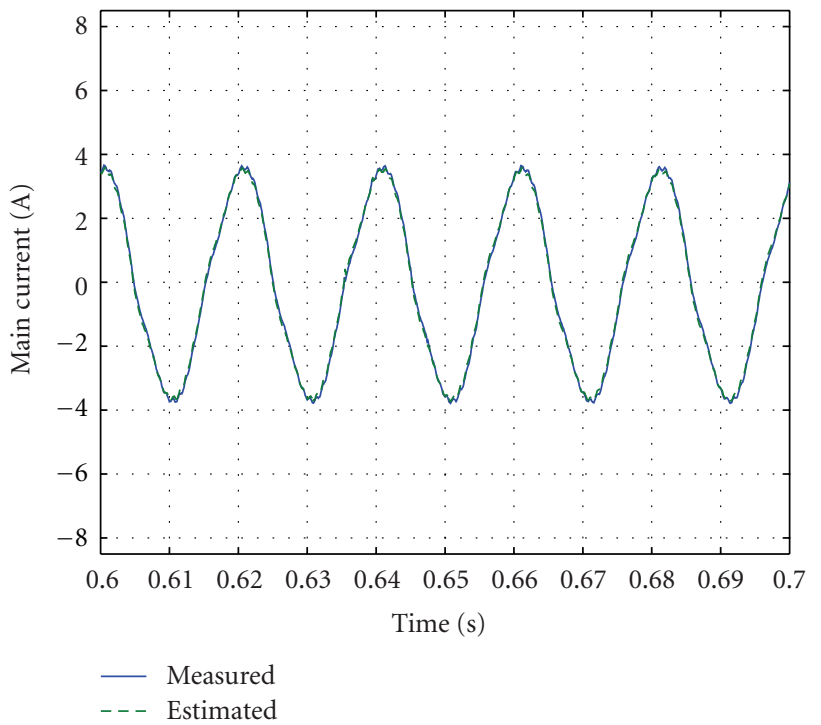

(d)

FIGURE 11: Measured and estimated stator currents of the SPIM during the step from $10 \mathrm{~Hz}$ to $50 \mathrm{~Hz}$ in the frequency stator (experimental results): (a) auxiliary winding $i_{s \alpha}$, (b) details of $i_{s \alpha}$ at $50 \mathrm{~Hz}$, (c) main winding $i_{s \beta}$, (d) details of $i_{s \beta}$ at $50 \mathrm{~Hz}$.

where the parameters of the equivalent circuit are evaluated from the experimental DC, locked rotor, and no-load tests [19]. An optical incremental encoder (SUMTAK Corporation, type LDA-001-1000 CE, 1024 pulses per revolution) is coupled to SPIM shaft in order to measure the rotational speed and compare it to its estimative. A magnetic powder brake Magtrol emulates the mechanical load. The SPIM windings are fed by two quadrature AC voltages with constant V/f ratio generated by an IGBT-based three-leg voltage source inverter (VSI) whose electrical characteristics are summarized in Table 2. The use of a three-leg inverter presents many advantages over a two-leg topology such as generate a zero voltage vector, avoid the circulation of an AC current in the DC link capacitor, and improve the output voltage quality in terms of harmonic distortion $[6,7,12,13]$. The integrated sensors to VSI are used to measure the currents of the main and auxiliary stator windings. The experimental implementation of the proposed observer is realized using a dSPACE DS1103 controller board, which allows a rapid realtime prototyping $[20,21]$. Since this hardware is linked to MATLAB/Simulink/Stateflow development software from MathWorks, a friendly interface can be used in order to set up and tune up the electrical drive and the parameters of the proposed observer. In this philosophy, the model of the proposed observer is converted into a discrete-time block diagram, which is introduced in Simulink, adequately compiled, and inserted in the DS1103, where the algorithm is executed to compute the rotor flux and rotational speed estimations based in the measured values acquired by A/D converters. This controller board also generates the PWM signals for the VSI driver and acquires the signal of an incremental encoder for speed measurement. The control desk provides a virtual 


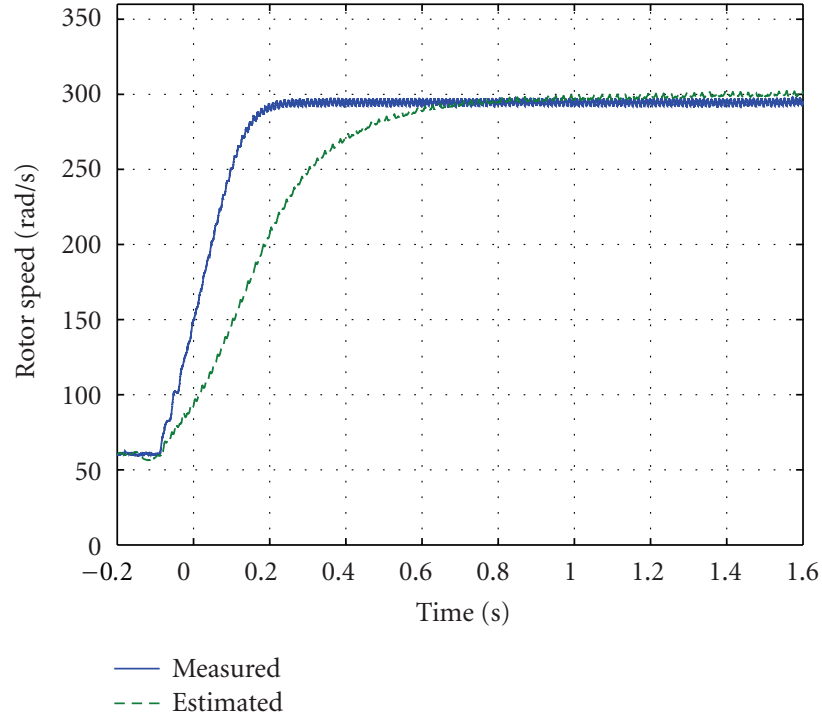

(a)

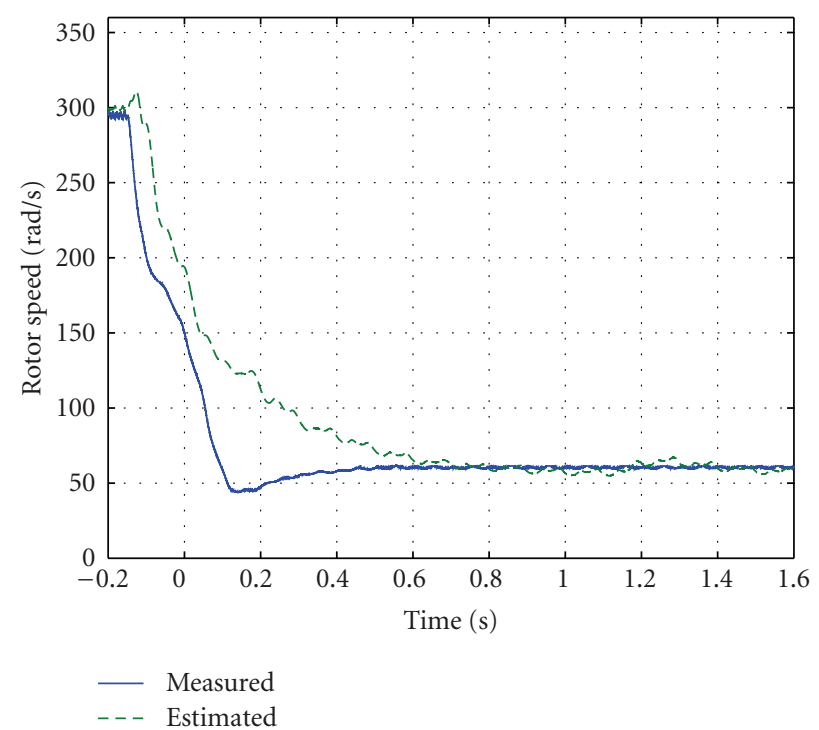

(b)

Figure 12: Estimated and measured rotor speed $\omega_{r}$ of the SPIM during the step in the frequency stator (experimental results): (a) from $10 \mathrm{~Hz}$ to $50 \mathrm{~Hz}$, (b) from $50 \mathrm{~Hz}$ to $10 \mathrm{~Hz}$.

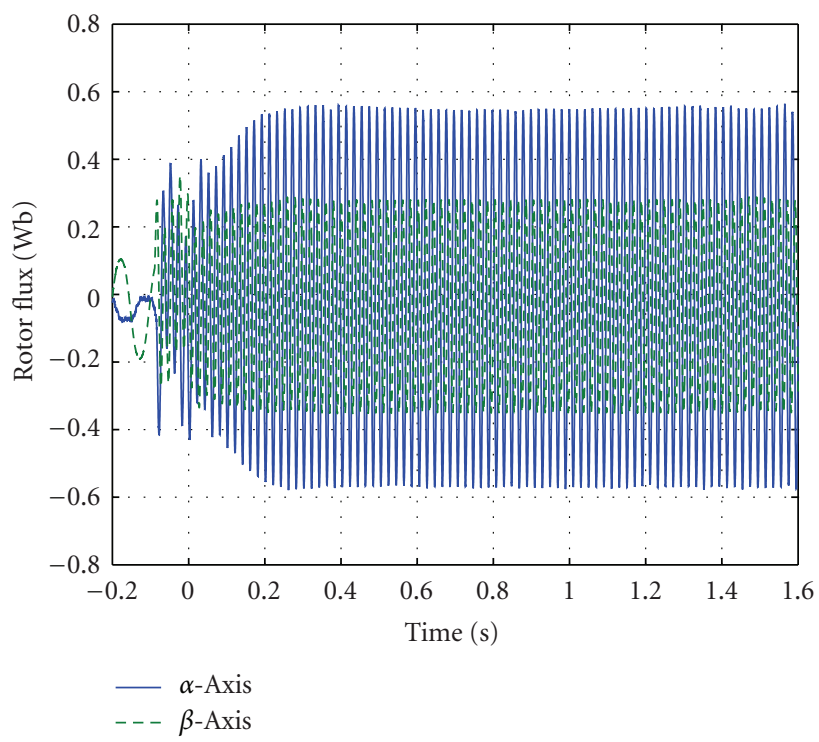

(a)

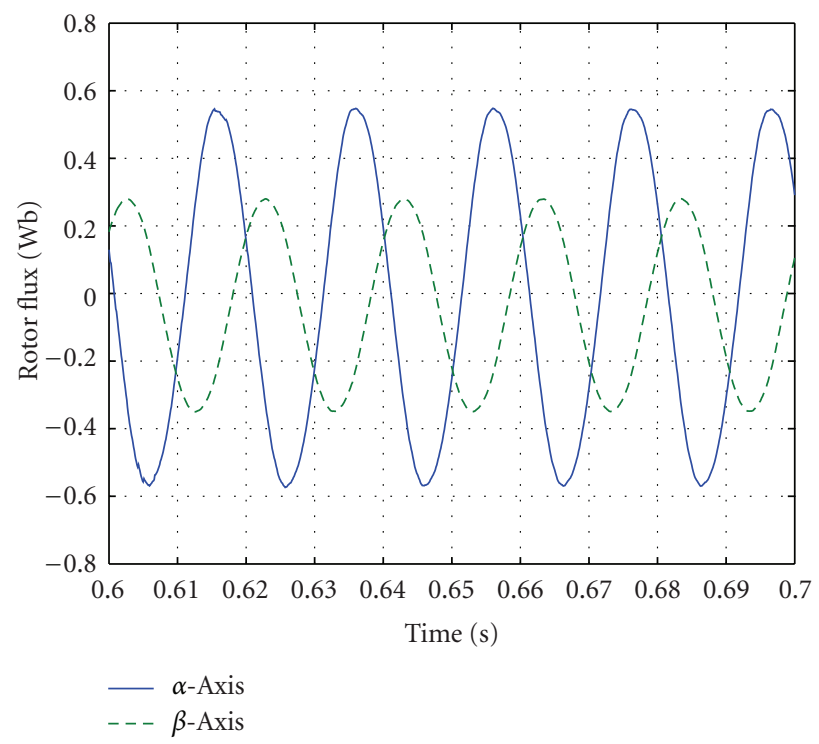

(b)

FIGURE 13: Estimated rotor fluxes $\lambda_{r}$ of the SPIM during the step from 10 to $50 \mathrm{~Hz}$ in the frequency stator (experimental results): (a) estimated rotor fluxes, (b) details of the estimated rotor fluxes at $50 \mathrm{~Hz}$.

instrument panel that enables the monitoring of measured and estimated variables and the adjustment of system values.

\section{Observer Performance}

5.1. Simulation Results. Considering the experimental apparatus presented in the last section, a computer simulation was done using MATLAB/simulink in order to verify the performance of the proposed observer. In the first test, the stator frequency of the no-load SPIM is varied from 10 to $50 \mathrm{~Hz}$ and from $50 \mathrm{~Hz}$ to $10 \mathrm{~Hz}$. The stator currents of the SPIM are shown in Figure 5. The auxiliary winding current $i_{s \alpha}$ is $0.40 A_{\text {rms }}$ at $10 \mathrm{~Hz}$, which is practically maintained at $50 \mathrm{~Hz}$. The main winding current $i_{s \beta}$ is $1.50 A_{\text {rms }}$, and increases to $2.70 A_{\text {rms }}$ at $50 \mathrm{~Hz}$. Although a delay is noted in the estimation, the proposed observer presents a good accuracy to estimate the stator currents of the SPIM with an error smaller than $8 \%$. The phase diagrams of the vector flux $\lambda_{r \alpha} \times \lambda_{r \beta}$ for $10 \mathrm{~Hz}$ and $50 \mathrm{~Hz}$ are presented in Figure 6, where 


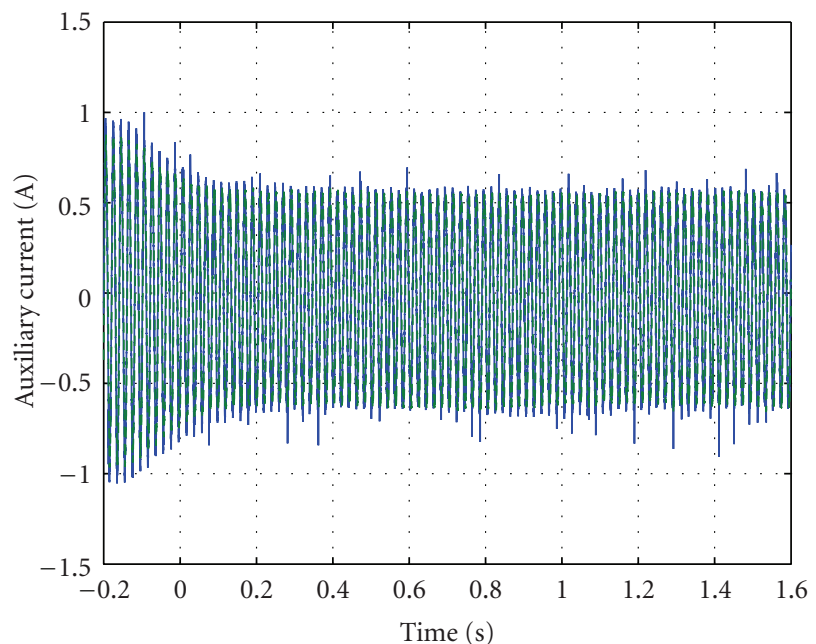

(a)

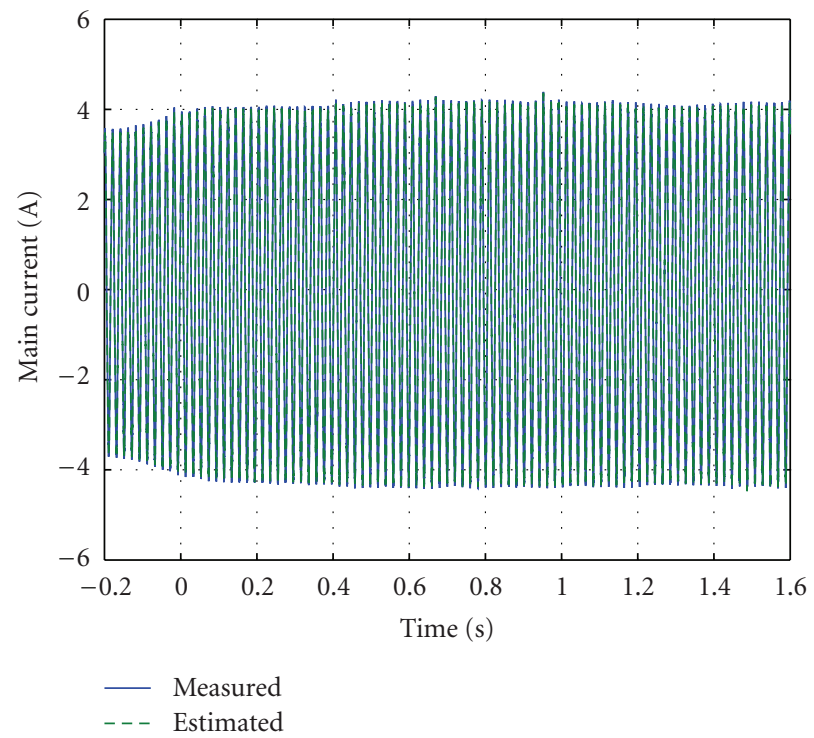

(c)

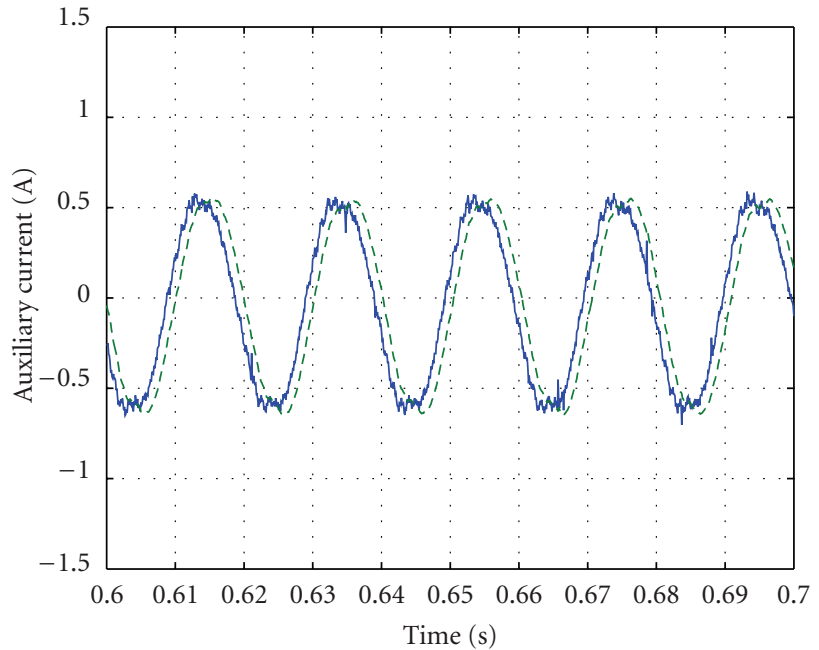

(b)

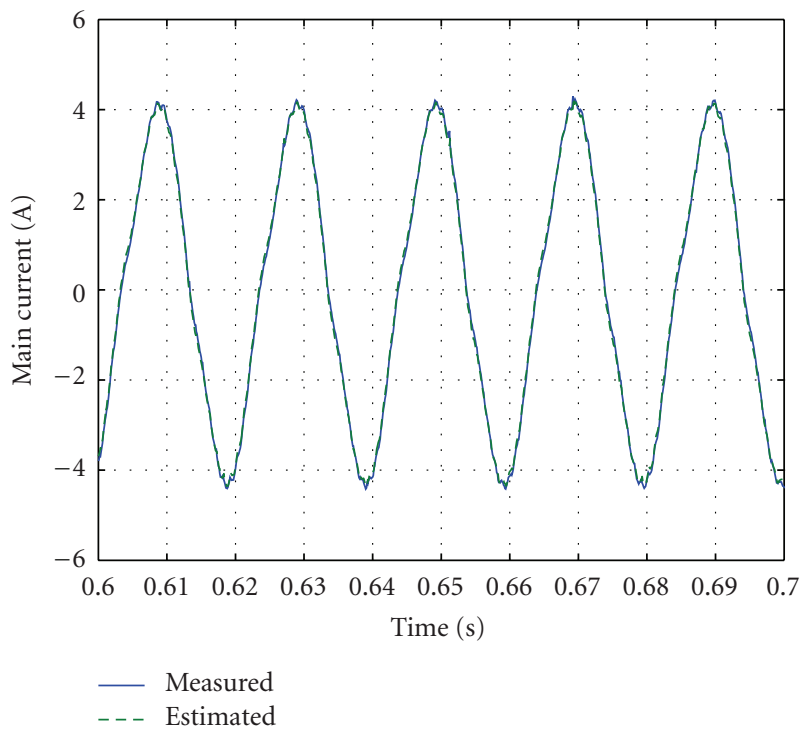

(d)

FIGURE 14: Measured and estimated stator currents of the SPIM when the rated mechanical load is applied (experimental results): (a) auxiliary winding $i_{s \alpha}$, (b) details of $i_{s \alpha}$, (c) main winding $i_{s \beta}$, (d) details of $i_{s \beta}$.

the maximum error $\Delta \lambda_{r}$ in the flux estimation is smaller than $8 \%$ and it is observed when the SPIM operates at $10 \mathrm{~Hz}$. This error in the flux estimative at lower frequencies can be justified by the presence of the high-pass filter in the observer structure, whose function is to prevent problems related to DC offset in the current sensors. The acceleration and deceleration of the SPIM are shown in the Figure 7, where a good agreement can be noted in steady state condition between the speed estimative $\hat{\omega}_{r \alpha}$ obtained from $\hat{\lambda}_{r \alpha}$ and the rotor speed of the SPIM $\omega_{r}$. Although $\hat{\omega}_{r \beta}$ obtained from $\hat{\lambda}_{r \beta}$ also has a good agreement with $\omega_{r}$ at high frequencies, this speed estimative presents an error at low frequencies which can be attributed to presence of the high-pass filter in the observer structure. The dynamic response of $\hat{\omega}_{r \beta}$ is more oscillatory than $\hat{\omega}_{r \alpha}$. It is also observed that the estimated values $\hat{\omega}_{r \alpha}$ and $\hat{\omega}_{r \beta}$ present a lag in relation to $\omega_{r}$, which is caused principally by the lowpass filters of the envelope detectors.

In the second simulated test, the rated mechanical load is applied to SPIM shaft when the a stator frequency is $50 \mathrm{~Hz}$. In this simulated situation, the application of mechanical load reduces the auxiliary winding current $i_{s \alpha}$ to $0.30 A_{\text {rms }}$ while the main winding current $i_{s \beta}$ is slightly increased to $2.80 A_{\mathrm{rms}}$ as presented in Figure 8. The error observed in the estimation of both currents is lower than $6 \%$. The phase diagram of the vector flux considering the loaded SPIM is presented in Figure 9, where it can be verified that the error in the flux estimations is smaller than $4 \%$. Considering Figure 10, the proposed observer provides accurate estimations for rotor speed $\omega_{r}$ in this simulated situation, with little delay and an error smallest than $3.75 \mathrm{rad} / \mathrm{s}$. 


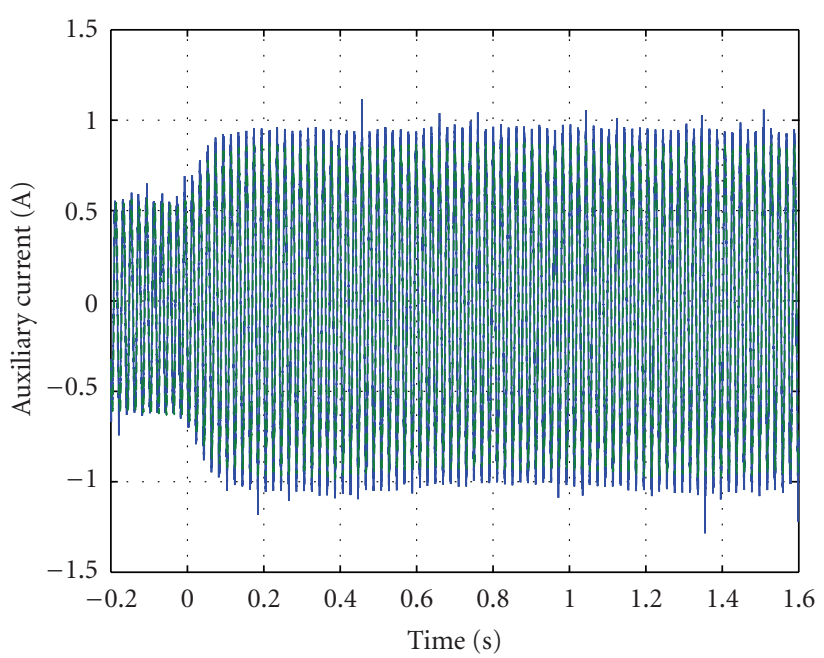

(a)

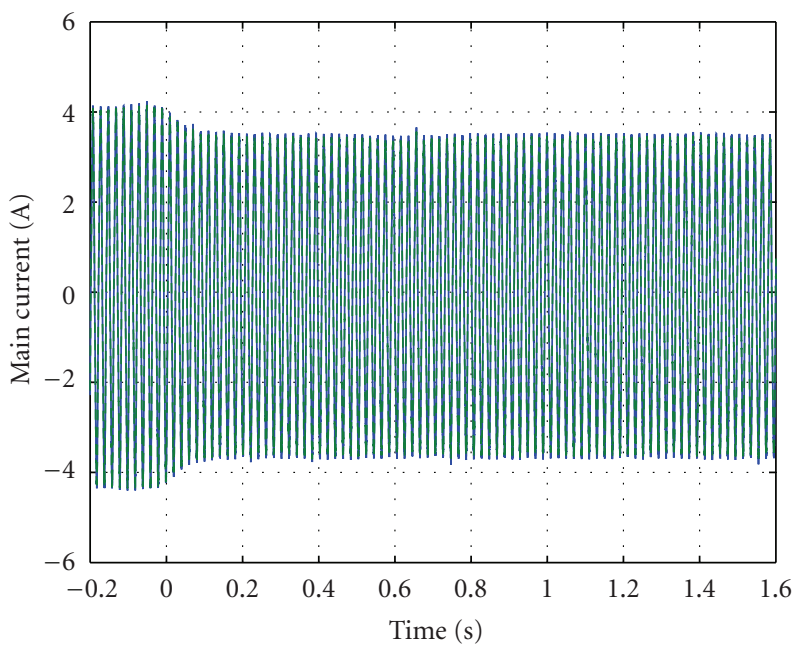

- Measured

- - Estimated

(c)

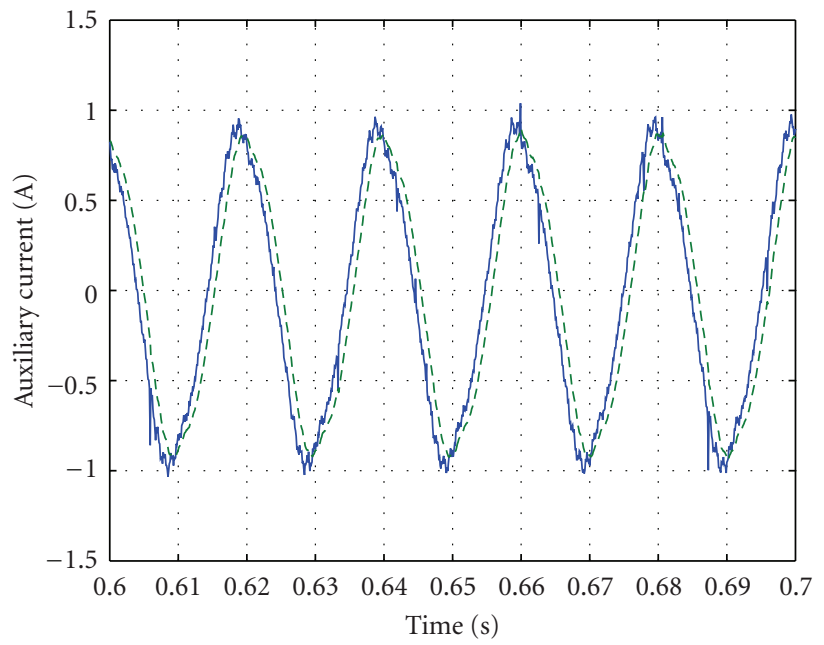

(b)

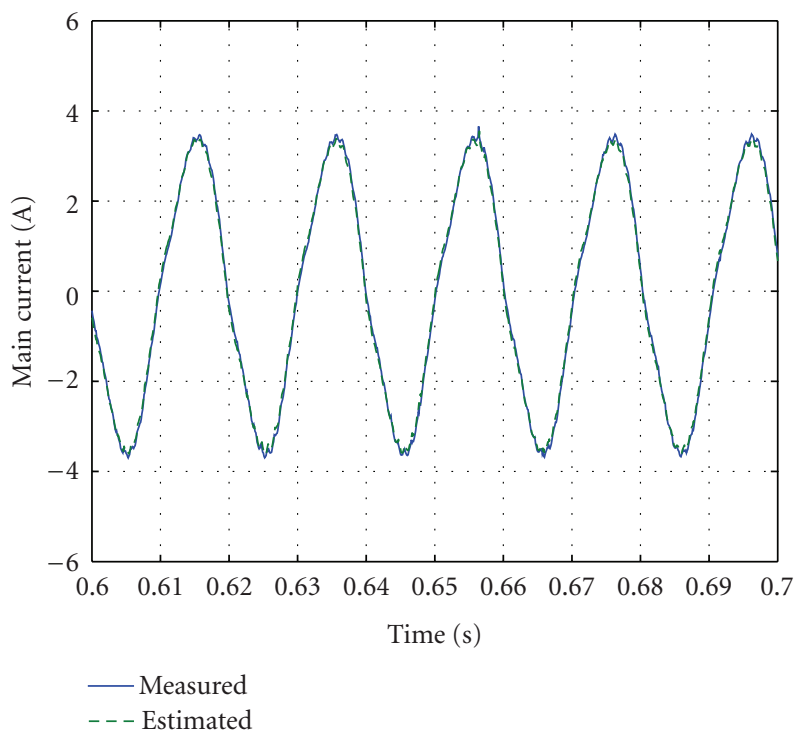

(d)

FIGURE 15: Measured and estimated currents of the SPIM when the rated mechanical load is removed (experimental results): (a) auxiliary winding $i_{s \alpha}$, (b) details of $i_{s \alpha}$, (c) main winding $i_{s \beta}$, (d) details of $i_{s \beta}$.

5.2. Experimental Results. In order to acquire the electrical and mechanical measurements, the "trigger" function of the virtual oscilloscope offered by the dSPACE system is used to register an event occurrence, causing the registrations with negative value for time intervals before the trigger event.

The first experimental test consists of the application of a step variation from 10 to $50 \mathrm{~Hz}$ in the stator frequency of the no-load SPIM. Both time response of the auxiliary winding current $i_{s \alpha}$ and main winding current $i_{s \beta}$ obtained in this test are shown in Figure 11, where it can be observed that the estimated currents are very close to the measured values, demonstrating a good accuracy of the proposed observer to estimate the stator currents. It is observed a delay in the estimation of the stator currents, which is negligible for $\hat{i}_{s \beta}$. The SPIM speed response stepwise is reported in Figure 12, where the estimated speed $\hat{\omega}_{r \beta}$ and the measured speed $\omega_{r}$ clearly present a good agreement in steady-state condition in the experimental acceleration and deceleration of the SPIM. The delay in the estimation of the speed can be attributed to the presence of the low-pass filters in the envelope detectors. Figure 13 shows the estimated fluxes $\hat{\lambda}_{r \alpha}$ and $\hat{\lambda}_{r \beta}$, which can be considered accurate since the proposed observer has obtained good estimations for stator currents and rotor speed in the acceleration and deceleration of the SPIM.

The second experimental test consists in to apply and remove the rated mechanical load of the SPIM, which is operating with a stator frequency of $50 \mathrm{~Hz}$. The auxiliary winding current $i_{s \alpha}$ is reduced while the main winding current $i_{s \beta}$ increases with the load application, as shown in Figure 14. The estimation error in the estimation of the stator currents disappears when the mechanical load is removed as presented in Figure 15. These figures also show that the 


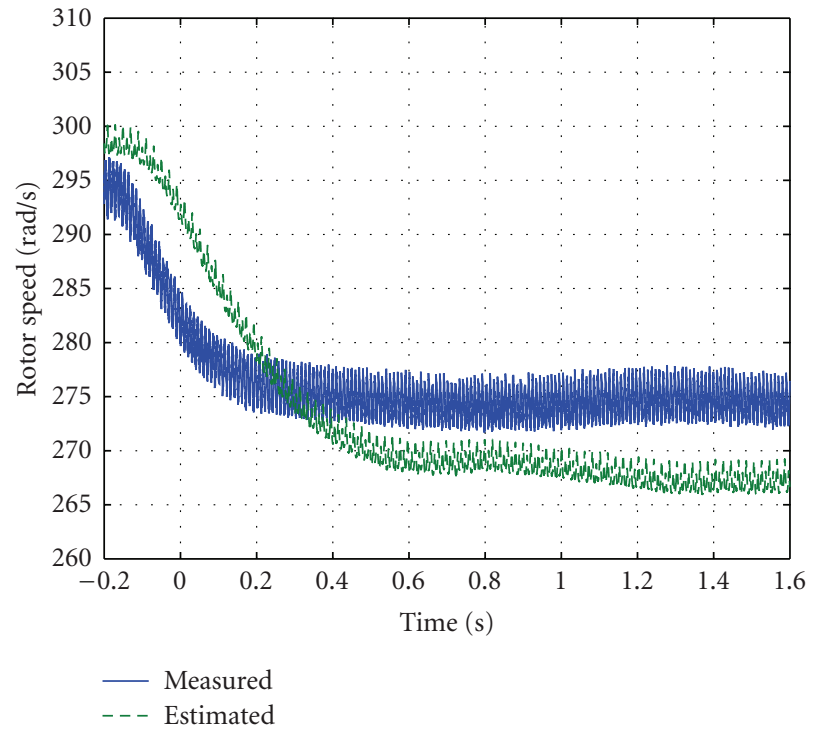

(a)

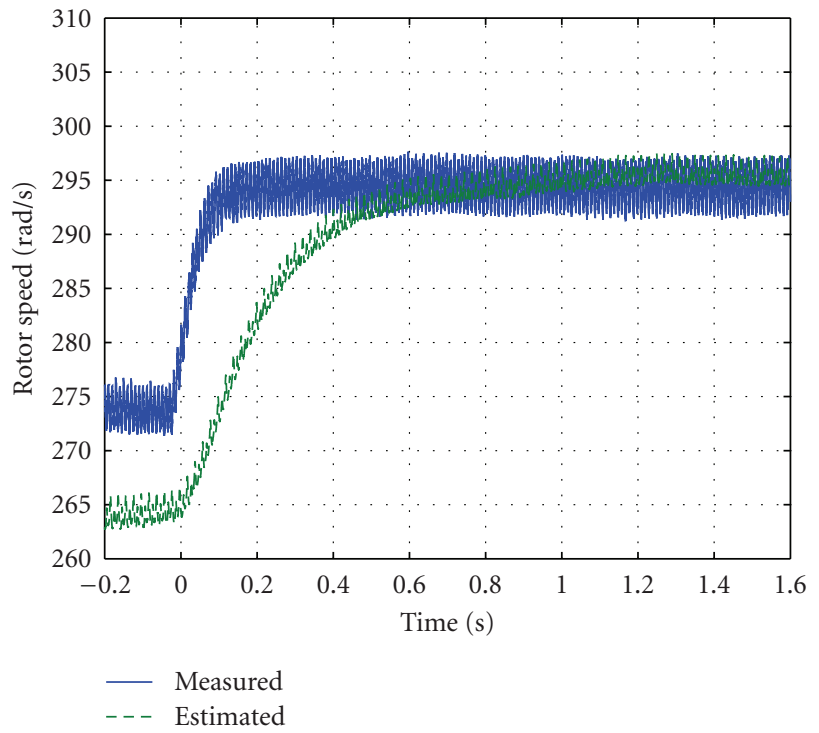

(b)

FIGURE 16: Measured and estimated rotor speed $\omega_{r}$ (experimental results): (a) when a mechanical load is applied to SPIM shaft, (b) when a mechanical load is removed of the SPIM shaft.

current estimations of the proposed observer are accurate and present a small delay, which is negligible for $\hat{i}_{s \beta}$. The effect of the mechanical load over the estimated speed $\omega_{r \beta}$ and the measured speed $\omega_{r}$ is shown in Figure 16, where is observed the presence of a little delay during the transient behavior and a small error between the estimated speed $\hat{\omega}_{r \beta}$ and the measured speed $\omega_{r}$ in steady-state, which is acceptable for the majority of the SPIM applications.

It is noted that the experimental results practically reproduce the computational simulations, whose differences can be justified by the uncertainties in the parameter estimation of the SPIM, which are greatest for the auxiliary winding and mechanical parameters. The experiments and the simulations demonstrate that the estimations of the stator currents and the rotor speed are satisfactory, indicating that the rotor flux estimation must be correct. Thus, the experimental performance of the proposed observer corroborates the computational simulations, demonstrating that it provides a satisfactory estimation for the rotor flux and the rotor speed of the SPIM with good accuracy within the usual frequency range considered for most SPIM application.

\section{Conclusion}

This paper presents the design, simulation, and implementation of a rotor flux and speed observer for the development of sensorless applications involving SPIMs. This observer is based in two half flux observers, which are designed using the stationary reference frame SPIM model. From these half flux observers, data are obtained in order to estimate the rotor speed of the SPIM. The performance of the proposed observer is computationally and experimentally evaluated considering two situations: a step variation in the stator fre- quency of the no-load SPIM and the application of mechanical load to SPIM shaft. The computational simulations and the experimental results present good agreement, demonstrating that the proposed observer provides satisfactory estimations of the rotor flux and rotor speed of the SPIM, with good accuracy within of the usual frequency range considered for most SPIM applications. In this context, the observer presented in this paper consists in an interesting option to estimate the rotor flux and/or rotational speed for sensorless applications involving the control of variable speed drives and/or development of optimization strategies for SPIMs.

\section{Acknowledgment}

The authors gratefully thank SDESLab (Sustainable Development and Energy Savings Laboratory), University of Palermo, for the support given during the experimental tests, and the financial support of MIUR (Ministero dell'Istruzione dell'Universitá e della Ricerca, Italy), CNPq (Conselho Nacional de Desenvolvimento Cientifico e Tecnológico, Brazil), CAPES (Coordenação de Aperfeiçoamento de Pessoal de Nivel Superior, Brazil), FAPEMIG (Fundação de Amparo a Pesquisa do Estado de Minas Gerais-Brazil) and Gorceix foundation (Brazil).

\section{References}

[1] T. A. Lettenmaier, D. W. Novotny, and T. A. Lipo, "Singlephase induction motor with an electronically controlled capacitor," IEEE Transactions on Industry Applications, vol. 27, no. 1, pp. 38-43, 1991.

[2] E. Muljadi, Y. Zhao, T. H. Liu, and T. A. Lipo, "Adjustable ac capacitor for a single-phase induction motor," IEEE Transactions on Industry Applications, vol. 29, no. 3, pp. 479-485, 1993. 
[3] H. M. B. Metwally, "New method for speed control of single phase induction motor with improved motor performance," Energy Conversion and Management, vol. 42, no. 8, pp. 941950, 2001.

[4] S. Vaez-Zadeh and A. Payman, "Design and analysis of sensorless torque optimization for single phase induction motors," Energy Conversion and Management, vol. 47, no. 11-12, pp. 1464-1477, 2006.

[5] E. R. Collins, "Torque and slip behavior of single-phase induction motors driven from variable-frequency supplies," IEEE Transactions on Industry Applications, vol. 28, no. 3, pp. 710 715, 1992.

[6] A. S. Ba-thunya, R. Khopkar, K. Wei, and H. A. Toliyat, "Single phase induction motor drives-a literature survey," in Proceedings of the IEEE International on Electric Machines and Drives Conference (IEMDC'01), pp. 911-916, Cambridge, Mass, USA, June 2001.

[7] M. B. de Rossiter Corrêa, C. B. Jacobina, A. M. N. Lima, and E. R. C. Silva, "A three-leg voltage source inverter for twophase AC motor drive systems," IEEE Transactions on Power Electronics, vol. 17, no. 4, pp. 517-523, 2002.

[8] D.-H. Jang and D.-Y. Yoon, "Space-vector PWM technique for two-phase inverter-fed two-phase induction motors," IEEE Transactions on Industry Applications, vol. 39, no. 2, pp. 542 549, 2003.

[9] M. B. de Rossiter Corrêa, C. B. Jacobina, E. R. C. Silva, and A. M. N. Lima, "Vector control strategies for single-phase induction motor drive systems," IEEE Transactions on Industrial Electronics, vol. 51, no. 5, pp. 1073-1080, 2004.

[10] R. Rocha, L. S. Martins Filho, and J. C. D. de Melo, "A speed control for variable-speed single-phase induction motor drives," in Proceedings of the IEEE International Symposium on Industrial Electronics (ISIE'05), pp. 43-48, June 2005.

[11] M. Jemli, H. B. Azza, and M. Gossa, "Real-time implementation of IRFOC for Single-Phase Induction Motor drive using dSpace DS 1104 control board," Simulation Modelling Practice and Theory, vol. 17, no. 6, pp. 1071-1080, 2009.

[12] M. Jemli, H. B. Azza, M. Boussak, and M. Gossa, "Sensorless indirect stator field orientation speed control for single-phase induction motor drive," IEEE Transactions on Power Electronics, vol. 24, no. 6, pp. 1618-1627, 2009.

[13] A. H. Rajaei, M. Mohamadian, S. M. Dehghan, and A. Yazdian, "Single-phase induction motor drive system using z-source inverter," IET Electric Power Applications, vol. 4, no. 1, pp. 17-25, 2010.

[14] B. Bose, Power Electronics and Variable Frequency DrivesTechnology and Applications, IEEE Press, 1997.

[15] J. Holtz, "Sensorless position control of induction motorsan emerging technology," IEEE Transactions on Industrial Electronics, vol. 45, no. 6, pp. 840-851, 1998.

[16] E. A. Vendrusculo and J. A. Pomilio, "An adaptive speed estimator for single-phase induction motors," in Proceedings of the International Symposium on Power Electronics, Electrical Drives, Automation and Motion (SPEEDAM'08), pp. 12481252, Ischia Naples, Italy, June 2008.

[17] M. Caruso, V. Cecconi, A. O. Di Tommaso, and R. Rocha, "A flux and speed observer for sensorless SPIM applications," in Proceedings of the 19th International Conference on Electrical Machines (ICEM'10), pp. 1-6, Rome, Italy, September 2010.

[18] P. Krause, Analysis of Electric Machinery, McGraw-Hill, New York, NY, USA, 1987.

[19] IEEE Standard test procedure for single-phase induction motors, IEEE Std 114-1982 (Revision of ANSI/IEEE Std 11419691), December, 1982.
[20] A. O. Di Tommaso and R. Miceli, "A new high accuracy software based resolver-to-digital converter," in Proceedings of the 29th Annual Conference of the IEEE Industrial Electronics Society (IECON'03), pp. 2435-2440, Industrial Electronics Society, November 2003.

[21] C. Cavallaro, A. O. Di Tommaso, R. Miceli, A. Raciti, G. Ricco Galluzzo, and M. Trapanese, "Analysis a DSP implementation and experimental validation of a loss minimization algorithm applied to permanent magnet synchronous motor drives," in Proceedings of the 29th Annual Conference of the IEEE Industrial Electronics Conference (IECON'03), vol. 1, pp. 312-317, 2003. 

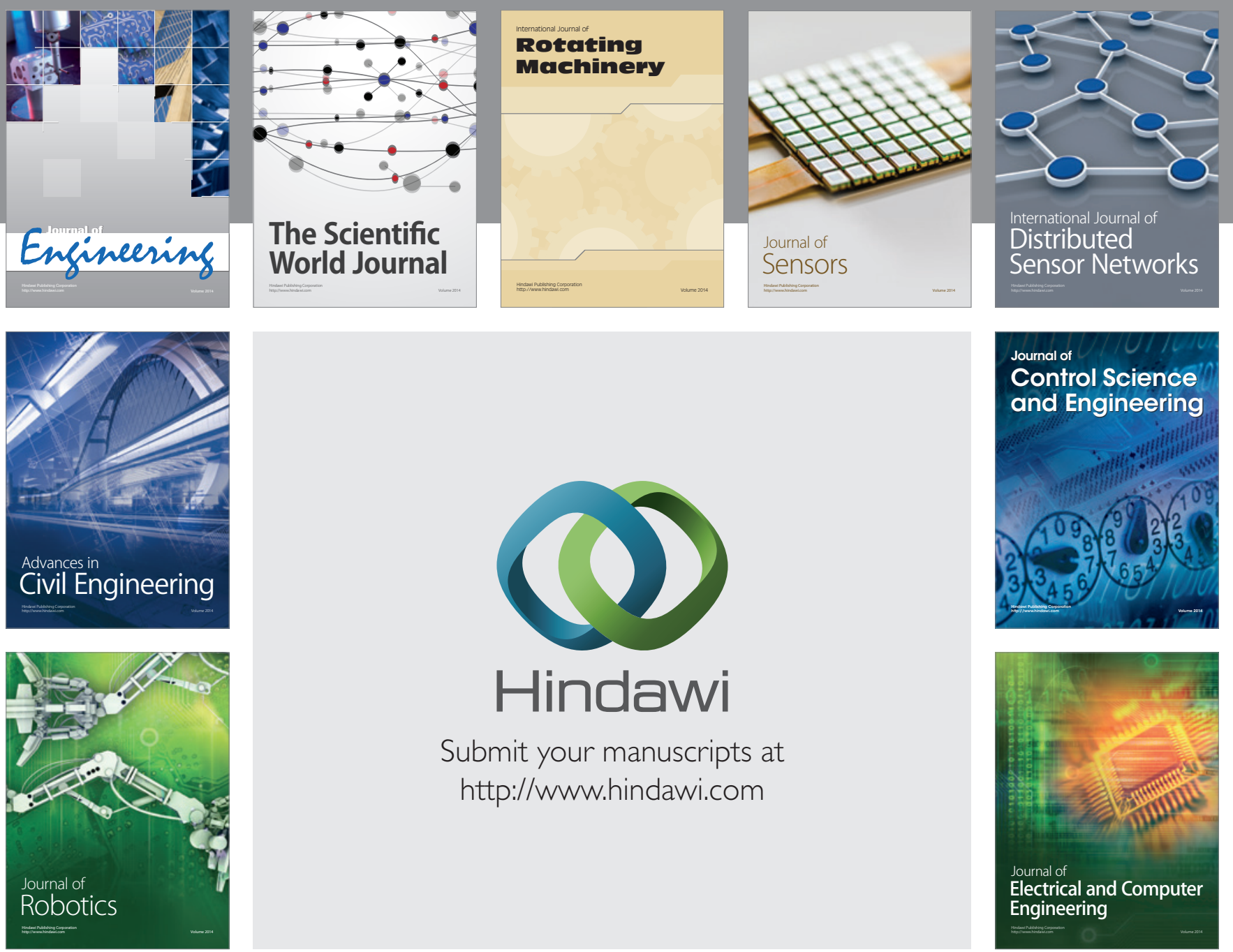

Submit your manuscripts at

http://www.hindawi.com
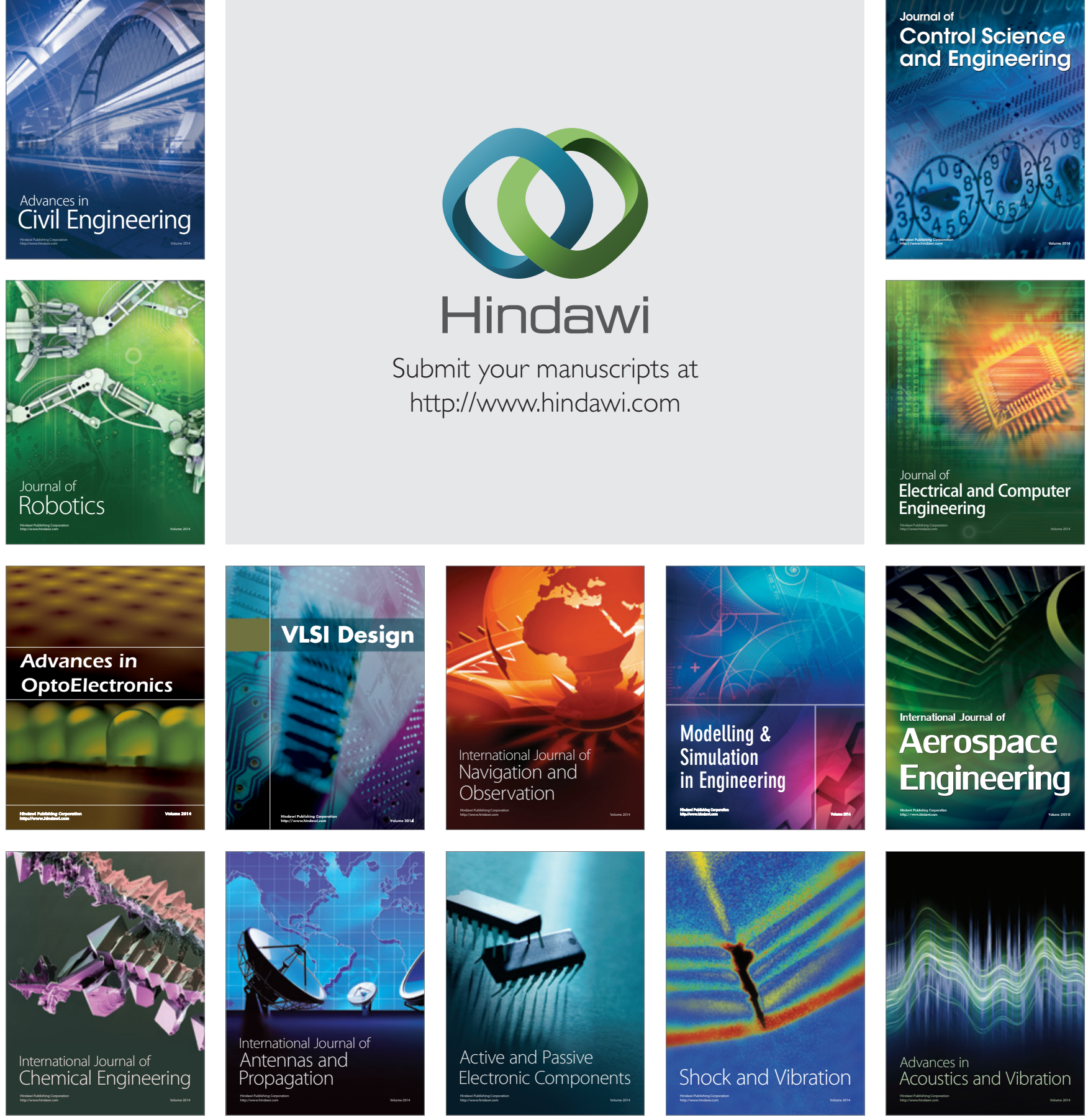